\title{
Control of FeAl Composition Produced by SPS Reactive Sintering from Mechanically Activated Powder Mixture
}

\author{
S. Paris, ${ }^{1,2}$ E. Gaffet, ${ }^{2}$ and F. Bernard ${ }^{1}$ \\ ${ }^{1}$ ICB UMR 6303 CNRS/Université de Bourgogne, 9. Avenue A. Savary, BP 47870, 21078 Dijon Cedex, France \\ ${ }^{2}$ IJL UMR 7198 CNRS/Université de Lorraine, Parc de Saurupt, CS 50840, 54011 Nancy Cedex, France
}

Correspondence should be addressed to F. Bernard; fbernard@u-bourgogne.fr

Received 19 February 2013; Revised 7 April 2013; Accepted 13 June 2013

Academic Editor: Claude Estournès

Copyright (C) 2013 S. Paris et al. This is an open access article distributed under the Creative Commons Attribution License, which permits unrestricted use, distribution, and reproduction in any medium, provided the original work is properly cited.

\begin{abstract}
The effects of mechanically activated powder mixture $(\mathrm{Fe}+\mathrm{Al})$ on the microstructure and the chemical composition of $\mathrm{FeAl}$ compound produced by reactive sintering implying an exothermic reaction were studied. Firstly, the characteristics of Fe/Al mechanically activated powder mixtures were investigated in terms of their phase composition and microstructure. The highenergy milling allowed the formation of micrometric agglomerates composed of nanometric crystallites of iron and aluminum. Three aggregate sizes class A: $\phi<125 \mu \mathrm{m}$, class B: $125 \mu \mathrm{m} \leq \phi<250 \mu \mathrm{m}$, and class C: $\phi \geq 250 \mu \mathrm{m}$ were considered. The latter class enhanced the reactivity of powder mixtures due to an increase of interfaces in contact as an analogy to nanostructured multilayer systems. Interrupted SPS experiments were performed on these mixtures to understand the origin of chemical heterogeneities observed after the reactive sintering. Formation of the intermediate phase $\mathrm{Fe}_{2} \mathrm{Al}_{5}$ at $\sim 510^{\circ} \mathrm{C}$ was accompanied by an exothermic reaction and a linear expansion and followed by the formation of small amount of FeAl. The conversion to FeAl was complete at temperatures higher than the melting point of $\mathrm{Fe}_{2} \mathrm{Al}_{5}\left(1170^{\circ} \mathrm{C}\right)$. Finally, a phase evolution between $\mathrm{Fe}$ and $\mathrm{Al}$ versus the temperature during the reactive sintering is suggested.
\end{abstract}

\section{Introduction}

Obtaining dense FeAl compounds with a perfectly controlled microstructure is of interest because of improved hardness and strength but also because of expectations of better ductility and toughness for these intrinsically brittle materials [1]. Techniques for producing ultrafine grained bulk materials have been extensively studied over the last decade [2-9]. They include consolidation from nanostructured milled powder by using conventional hot compaction $[2,3]$, thermal spraying by different processes such as high velocity oxy-fuel (HVOF) [4-6] as well as the spark plasma sintering (SPS) [7-9]. Prior works reported that SPS was an effective method for the synthesis of monolithic FeAl compounds using powders prepared via ball-milling [10-12]. Consequently, it is crucial to control the microstructure of mechanically activated powder mixtures (called hereafter MAP-mixture) which can be considered as agglomerates composed of nanoreactants. Such MAP-mixtures are reported to be combustion synthesis nanoreactors [13]. Indeed, the combustion front reaction propagates in individual aggregate from the surface to the core. In addition, this fine multilayers system inside MAagglomerates allows to improve the combustion synthesis parameters such as an increase of the combustion front velocity (by a factor 3 or 5 in the case of Mo/2Si [14] and of $\mathrm{Fe} / \mathrm{Al}$ systems, resp. [15]) or decrease the ignition temperature of the exothermic reaction between $\mathrm{Fe}$ and $\mathrm{Al}$ by $100^{\circ} \mathrm{C}$ down to about $400^{\circ} \mathrm{C}$ [16]. However, the decrease of the grain size down to the nanometer scale is not the only pertinent parameter. Indeed, the quality and the size of the exchange surface between reactants are essential, especially when a mechanical pressure is applied during a liquidsolid reaction [17]. Such contacts between particles play a major role in the heat conduction and the kinetics of the reaction. For example, in contrast to combustion synthesis of MAP-mixtures, the reaction from $\mathrm{Fe} / \mathrm{Al}$ nanostructured powders prepared by evaporation-condensation in cryogenic media [18] leads to the formation of alumina with some minor FeAl compounds [19]. The purpose of this work is to control the characteristics (morphology, structure, chemical 
composition, analogy with fine multilayers systems without any mechanical alloyed phases) of mechanically activated powder mixtures. In addition, to understand the origin of the FeAl chemical heterogeneities, SPS-stop experiments (i.e., when the current is switched off) were performed at desired temperatures determined from the SPS shrinkage curve. Consequently, each stage of the synthesis and the consolidation of FeAl by SPS reactive sintering were investigated.

\section{Experimental Procedure}

The synthesis process to produce dense nanostructured $\mathrm{FeAl}$ from elemental powders $(\mathrm{Fe}+\mathrm{Al})$ is composed of two steps [20]: (i) mechanical activation of the elemental powder mixture by a short duration treatment in a high energy planetary ball-mill and, (ii) synthesis and densification of $\mathrm{FeAl}$ in one step by reactive sintering using SPS equipment.

The $\mathrm{Al}$ and $\mathrm{Fe}$ reactants are taken in the stoichiometric ratio 53 at.\% Fe. $10 \mathrm{~g}$ mixture of elemental powders of $\mathrm{Al}$ (Cerac, $15-20 \mu \mathrm{m}$ in particle size, and $99.5 \%$ purity) and $\mathrm{Fe}$ (Prolabo, $10-15 \mu \mathrm{m}$ in particle size, and $99.5 \%$ purity) was comilled in confined air via a planetary ball vario-mill Fritsch Pulverisette $4[22,23]$. Based on previous works $[10,16]$, a specific ball-milling condition was established at $150 \mathrm{rpm}$ (rotation per minute) for the disk rotation speed, $-200 \mathrm{rpm}$ for the absolute vial rotation speed, and $4 \mathrm{~h}$ uninterrupted milling duration. The charge ratio $\mathrm{C}_{R}$ (ball to powder mass ratio) was 7 . The powders being constituted of quite abrasive materials, a short duration of milling has been selected to avoid any contamination of the product by the milling tools. In fact, in order to limit the powder contamination by the milling tools but also to increase simultaneously the yield of MAP-mixtures, three millings without cleaning milling tools have been carried out. Indeed, under these conditions, the ductile character of powders induced the formation of $\mathrm{FeAl}$ coating on the vial surface aging as a protective liner against the abrasion on the surface of tempered steel tools. In addition, the milling parameters were selected to be short to avoid the formation of mechanically induced phases but still sufficiently long for producing MA-agglomerates. In fact, fracture and welding are the two basic events which cause a permanent exchange of matter between particles and ensure a mixing of components at a nanometer scale level $[10,16]$. To perform study of the aggregate size effect, two sieves of 125 and $250 \mu \mathrm{m}$ mesh size were selected in order to prepare three granulometric classes.

Then, these MA-powders were introduced in the SPS apparatus [24] for performing reactive sintering implying an exothermic reaction. The mechanically activated powders were first cold compacted into green body in a cylindrical graphite die lined with graphite foil using a uniaxial pressure of $80 \mathrm{MPa}$ during $2 \mathrm{~min}$. The relative density of the green sample resulting from the cold compaction was about $70 \%$, determined by geometrical measurements. The graphite die containing the cold-compacted sample was set inside the SPS chamber. SPS process is a pressure-assisted pulse-current sintering in which by repeated application of DC pulses, spark point discharges and Joule heating points result in efficient sintering with low power consumption. The experimental procedure is well detailed elsewhere [11]. A uniaxial pressure of $14 \mathrm{kN}$ (i.e., $70 \mathrm{MPa}$ ) was applied both during the reaction and during the cooling. A high DC current was generated, increasing from 0 to $1750 \mathrm{~A}$ in $20 \mathrm{~s}$ then held at the maximum value for $160 \mathrm{~s}$. Thus, the total duration for applying DC pulse current from the beginning of the heating to the beginning of the cooling is equal to 4 minutes. Temperatures were measured by means of a K-type thermocouple inside a hole located at $3 \mathrm{~mm}$ of sample surface. The end-products were typically disks of $18.8 \mathrm{~mm}$ in diameter and from 2.2 up to $5.5 \mathrm{~mm}$ in height. Before characterization, samples were first polished with 180-grit silicon carbide and down to $1 \mu \mathrm{m}$ with diamond paste and, finally cleaned in an ultrasonic ethanol bath in order to remove surface contamination from graphite foil. The density of sintered products was evaluated by Archimede's method.

For each "quenched" sample corresponding to SPS stop experiments, a phase and a chemical analysis were carried out, respectively, by X-ray diffraction (XRD) and by scanning electron microscopy (SEM). These quenching means freezing the different stages from shrinkage curve at desired temperatures of the SPS process by shutting off the electric current. Xray powder diffraction (XRD) measurements were performed using a D5000 Siemens high-resolution diffractometer with a monochromatic $\mathrm{Cu}-\mathrm{K}_{\beta}$ beam $(\lambda=0.1392 \mathrm{~nm})$ focused with a secondary curved graphite monochromator. Pattern decomposition was achieved by means of the profile-fitting. At the same time, a least-square refinement program was used to determine the cell parameter of reactants. A JEOL 6400F Scanning Electron Microscope (SEM) with a field emission gun (FEG) and coupled with a LINK OXFORD Energy Dispersive X-Ray Spectrometry (EDXS) was used to analyze, respectively, the grain morphology and the local chemical composition of materials. Consequently, MAP-mixtures were embedded and polished whereas dense materials were cut along the axial direction and were embedded in carbon charged resin (Konductomet). A back-scattered electron (BSE) technique was also used to determine the elemental chemical distribution. To estimate the global chemical composition, EDXS measurements were also performed on FeAl products annealed at $950^{\circ} \mathrm{C}$ in vacuum during 48 hours in order to get a reference material; these analyses were performed on square surfaces $\left(100 \times 100 \mu \mathrm{m}^{2}\right)$. The chemical composition was determined from 50 measurements. An ICP plasma torch (ICP OES Vista Pro commercialized by Varian) coupled with a Meinhardt nebulizer and cyclonic chambers $(200 \mathrm{kPa}, 1.3 \mathrm{~kW})$ was also used to check the $\mathrm{Fe}$ and $\mathrm{Al}$ contents.

\section{Results and Discussion}

3.1. The MAP-Mixture. The microstructure analysis deduced from XRD, SEM, and ICP experiments of all MAP-mixtures including polydisperse mixture is reported in Table 1. In comparison with the classical mixture (Turbula) composed of micrometer sized grains $(10-15 \mu \mathrm{m}$ and $20 \mu \mathrm{m}$ for $\mathrm{Fe}$ and $\mathrm{Al}$, resp.) [15], the mechanical activation stage allows 
TABLE 1: Average characteristics in terms of chemical composition and microstructure parameters (crystallite size, microdistortion level, and lattice parameter) for each class of MAP-mixtures $(\mathrm{Fe}+\mathrm{Al})$ in comparison with those obtained by a TURBULA classical mix. $\mathrm{a}_{\mathrm{JCPDS}} \mathrm{Al}=$ $0.4049 \mathrm{~nm}, \mathrm{a}_{\text {JCPDS }} \mathrm{Fe}=0.2866 \mathrm{~nm} .{ }^{*}$ Average characteristics $i=\sum$ (Characteristic $i \times$ yield of each granulometric class). ${ }^{\star}$ Grain size given by suppliers.

\begin{tabular}{|c|c|c|c|c|c|c|}
\hline \multirow{3}{*}{ Characteristics } & \multirow{3}{*}{ TURBULA powders } & \multicolumn{5}{|c|}{ MA powders resulting from the third ball-milling } \\
\hline & & \multicolumn{2}{|c|}{ Polydispersity } & \multicolumn{3}{|c|}{ Seaved_grain-size ranges $\Phi(\mu \mathrm{m})$} \\
\hline & & Average* & 3rd milling & Class $\mathrm{A}<125$ & Class B $125-250$ & Class $\mathrm{C} \geq 250$ \\
\hline Yield (\%) & $100 \%$ & & $96 \%$ & $8 \pm 4$ & $17 \pm 2$ & $75 \pm 03$ \\
\hline \multicolumn{7}{|l|}{ Chemical composition } \\
\hline Global_-ICP (\%at. Fe) & $53 \pm 1$ & $53 \pm 3$ & $53 \pm 3$ & $45 \pm 3$ & $47 \pm 4$ & $55 \pm 3$ \\
\hline Global-EDXS (\%at. Fe) & $53 \pm 1$ & $53 \pm 2$ & $53 \pm 2$ & $46 \pm 2$ & $49 \pm 2$ & $54 \pm 1$ \\
\hline \multicolumn{7}{|l|}{ Microstructure } \\
\hline \multicolumn{7}{|l|}{$\mathrm{Fe}$} \\
\hline Crystallite size (nm) & $10-15 \mu \mathrm{m}^{\star}$ & 53 & 50 & $90 \pm 5$ & $67 \pm 4$ & $45 \pm 3$ \\
\hline Microdistortion level (\%) & & 0.13 & 0.13 & 0.10 & 0.12 & 0.14 \\
\hline Lattice parameter (nm) & $0.2866(3)$ & $0.2867(1)$ & $0.2867(2)$ & $0.2866(9)$ & $0.2867(4)$ & $0.2868(3)$ \\
\hline \multicolumn{7}{|l|}{$\mathrm{Al}$} \\
\hline Crystallite size (nm) & $20 \mu \mathrm{m}^{\prime}$ & 70 & 70 & $110 \pm 7$ & $87 \pm 5$ & $62 \pm 3$ \\
\hline Microdistortion level (\%) & & 0.09 & 0.08 & 0.08 & 0.08 & 0.09 \\
\hline Lattice parameter $(\mathrm{nm})$ & $0.4049(2)$ & $0.4049(9)$ & $0.4050(4)$ & $0.4050(2)$ & $0.4050(6)$ & $0.4049(7)$ \\
\hline
\end{tabular}

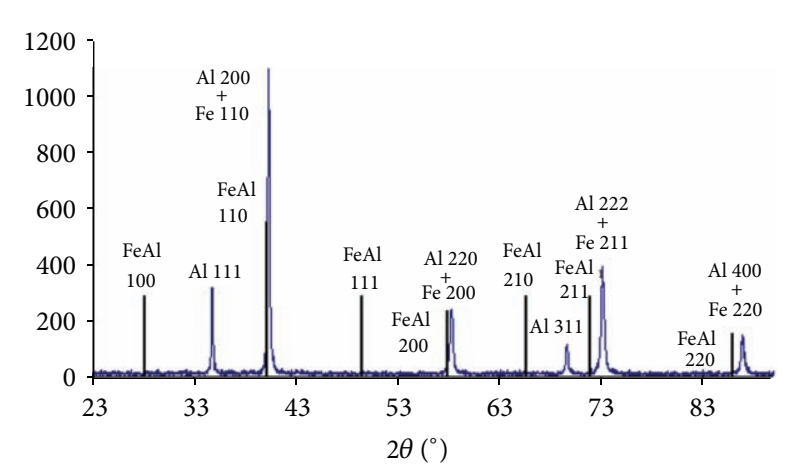

FIGURE 1: X-ray diffraction pattern of Fe/Al MAP-mixtures (theoretical XRD peak position of FeAl phase from ICDD n 01-1257).

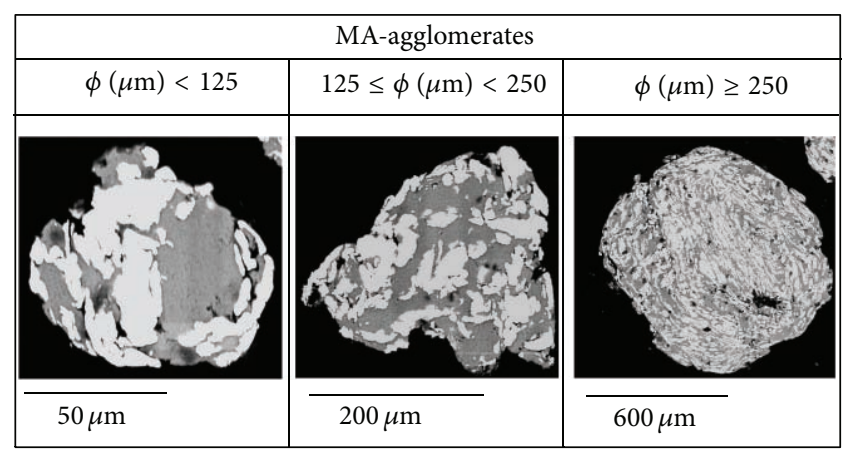

FIGURE 2: SEM (BSE mode) micrographs showing and comparing different morphologies of MAP-mixtures (53 at.\% Fe/ $\mathrm{Al}$ ) in function of the granulometry class (P4 (150/-200/4h)). The bright layers and the dark ones are $\mathrm{Fe}$ and $\mathrm{Al}$ phase, respectively [21].

the formation of micrometer size MA-powders (ranging from $0.4 \mu \mathrm{m}$ up to $800 \mu \mathrm{m}$ ) constituted of $\mathrm{Fe}$ and $\mathrm{Al}$ with an average crystallite sizes of $50 \mathrm{~nm}$ and $70 \mathrm{~nm}$, respectively.
The size distribution of MAP-mixtures is very wide and may be responsible for some heterogeneity after SPS reactive sintering. Taking into account the detection limit of the apparatus, XRD patterns which performed MAP-mixtures confirm that no mechanical alloyed phase is formed during the milling (Figure 1). In fact, only Fe and Al XRD peaks were observed and any modification of the lattice parameters of these phases was highlighted. The internal microstructure of the MA powders depended on the aggregate size (Figure 2). From chemical composition, microstructure, and structure, the yield of each aggregate size was calculated (Table 1). The yield was improved when the size of MA-powders increased; as an example $75 \%$ of MAP-mixtures had larger size than $250 \mu \mathrm{m}$. The size difference can be explained by an activation degree of powder which increases with the agglomerate size. This operation allowed selecting three classes of MAagglomerates, having different particle sizes: (i) class A: $\phi<$ $125 \mu \mathrm{m}$, (ii) class B: $125<\phi<250 \mu \mathrm{m}$, and (iii) class C: $\phi>$ $250 \mu \mathrm{m}$. A fourth batch of powder labeled as "polydisperse" was also studied, that is, without any size separation.

From SEM observations of the MA-aggregate crosssections (Figure 2), it is obvious that the morphology and the microstructure between each class are heterogeneous and may be responsible for the chemical contrast observed in sintered products $[10,12]$. Indeed, SEM observations of MA-agglomerates (Figure 2) revealed that the chemical distribution between $\mathrm{Fe}$ (white color) and $\mathrm{Al}$ (dark color) is different from one type of aggregates to another one. Even after a mechanical activation step, the initial grain size of Fe $(10-15 \mu \mathrm{m})$ and $\mathrm{Al}(20 \mu \mathrm{m})$ is still observed in smaller MAaggregates (Class A, Figure 2(a)). In addition, concerning the medium MA-agglomerates (Class B, Figure 2(b)), some grains of $\mathrm{Fe}$ and $\mathrm{Al}$ are slightly elongated and had a thickness in the range of few micrometers. Finally, only large MAaggregates (i.e., Class C, Figure 2(c)) may be considered 
as $\mathrm{Fe} / \mathrm{Al}$ multilayers. Indeed, this latter is comparable to the $\mathrm{Fe} / \mathrm{Al}$ diffusion couples. Moreover, a variation of the aggregate morphology inside this lamellar structure can be observed on the larger agglomerate (Class C). The analogy with multilayers structure is improved from the surface to the center of the agglomerate. In comparison to the initial powders, the thickness reduction of $\mathrm{Al}$ elongated grains (i.e., layers) is greater than those of Fe especially at the center of aggregates (i.e., ranging from $100 \mathrm{~nm}$ to $500 \mathrm{~nm}$ ). Similar behavior has been reported for other systems such as $\mathrm{Al}-\mathrm{Cr}$ [25] and Al-Mo [26]. In the center of agglomerate, it can be assumed that the microstructure of the powder particles could not be solved using SEM, since the size of layers has been reduced below 0.2 micrometer. Between the finest multilayers, it is possible to distinguish the presence of a new intermediate color (gray) (Figure 3(a)) that consisted of 53 at.\% Fe from chemical analyses (Figure 3(b)). These confirm the well-established Fe/Al diffusion couples, the improvement of powder reactivity, and, therefore, the conversion rate. In fact, according to Fe/Al binary phase diagram [27] and to the schematic diagram showing the possible hierarchy of phase formation in the case of a diffusion couple [28], this interfacial intermediate phase may correspond to an amorphous phase, a $\mathrm{Fe}$ or $\mathrm{Al}$ rich solid solution, and/or another intermetallic phase like $\mathrm{Fe}_{2} \mathrm{Al}_{5}$ formed at higher temperature [29]. This latter intermetallic is assumed to form after an annealing of $\mathrm{Fe} / \mathrm{Al}$ multilayer thin films [30].

From Table 1, the crystallite sizes of reactants are in the nanometric range for both $\mathrm{Al}$ and $\mathrm{Fe}$ parts. In particular, the crystallite size of $\mathrm{Fe}$ (idem for $\mathrm{Al}$ ) decreases when the size of MA-aggregates increases whereas the Fe microdistortion rate decreases (no evolution is observed for $\mathrm{Al}$ ). In addition, whatever the granulometry, overestimated value of aluminum amount (70 at.\%) was determined. Similar results were obtained for powders mixed during $4 \mathrm{~h}$ in Turbula. This difference can be explained by the higher analyzed XRD depth ( 7 times) of $\mathrm{Al}(30 \mu \mathrm{m})$ in comparison with that of $\mathrm{Fe}$ $(2.4 \mu \mathrm{m})$ for a similar fraction of irradiated area. Nevertheless, as the Fe particles seem to be embedded by an aluminum layer, a careful interpretation is needed. In addition, whatever the granulometry, no contamination (mainly by $\mathrm{Cr}$ ) from milling tools has been observed (Figure 3(b)). Nevertheless, the global chemical analysis of aggregate shows a significant amount of oxygen $(<10$ at.\%) which increases with the grain size, that is, 5, 7, and 9 at.\% for the smallest (Class A), the medium (Class B), and the larger (Class $\mathrm{C}$ ) agglomerates, respectively. Similar results were reported by Godlewska et al. [31]. However, the origin of the oxygen may be due to the milling atmosphere (confined air) containing oxygen. Nevertheless, these oxides are not detected by XRD (in the detection limit of the apparatus). This study confirms the interest to use high-energy ball-milling without cleaning vials in order to avoid any contamination. Moreover, the formation of passive layer around the micrometric aggregate surface will reduce considerably the reactivity towards ambient air of the isolated nanometric particles allowing storage, transport, and handling.
Although the ball-milling conditions are identical for each granulometric class (P4 (150/-200/4 h), noticeable heterogeneities have been found to appear whatever the scale observation (from macroscopic to microscopic levels) in micrometric Fe/Al MA-aggregates. Transverse observations have shown that aggregates are heterogeneous and that they are responsible for the chemical contrast present on reactive sintered compound. Similar behavior was observed in the case of the Mo/2Si agglomerates [32]. Heterogeneities of $\mathrm{Fe} / \mathrm{Al}$ aggregates depend on their size. Consequently, the control of the MA-aggregates features (chemical composition, microstructure, intergranular porosity, etc.) is crucial in order to elaborate intermetallic compounds with expected properties. Such a result is emphasized because $\mathrm{Fe} / \mathrm{Al}$ MA-aggregates can be considered as combustion synthesis nanoreactors [13]. To adjust the specific characteristics of MA-aggregates for expected foreseen applications, it is necessary to understand the origin of such heterogeneities. A similar behavior, that is, the observation of heterogeneous micrometric aggregates composed of nanostructured reactants was already reported in the case of the production of items from cold-rolling process [33]. A nanometer size multilayers system and the chemical homogeneity are obtained when the number of cycle is increased and when the mechanical pressure is higher. Consequently, it is possible to assume that the difference of MA-aggregate characteristics must be due to a modification of plastic deformation mechanism during the ball-milling process $[34,35]$. In MA techniques, the repeated fracture-welding process results in an intimate mixture of the two constituents with a concomitant increase of the defect concentration and strain in the mixture. In the case of ductile-ductile powder mixture (such as $\mathrm{Fe} / \mathrm{Al}$ system), milling refines the grain size further to a lamellar structure and even greater number of defects are introduced [36-38]. Ball-milling conditions have an influence on the nature and, also on the concentration of defects and, consequently on the chemical homogeneity. High energy planetary ball-mill (especially pulverisette $\mathrm{P} 4$ ), in which the rotation speeds of vials and the plate can be selected independently, allows extending the milling investigation for producing powders with the desired characteristics [39-44]. Oleszak and Shingu [34] reported that the shape of agglomerates with different chemical composition from 50 to 100 at.\% Fe is more regular when the milling duration is prolonged. According to ElEskandarany et al. [45], the large distribution of the MAaggregates size indicates that the growth mechanism of aggregates to obtain powders with optimal characteristics is not complete. It can be stipulated that the heterogeneity can be due to a difference of co-milling effective duration. Milling injects an additional energy to the reactant system in the form of the interfacial and strain energies and effectively lowers the activation barriers. In fact, in a few minutes to one hour, the lamellar spacing (Figure 3(a)) usually becomes small (few micrometers) and the crystallite size is refined to nanometric dimensions. Moreover, the presence of structural defects (i.e., dislocations, vacancies, staking faults, grain boundaries, etc.) enhances the diffusivity of dissolved elements into the matrix. Additionally, the slight temperature increase during milling 


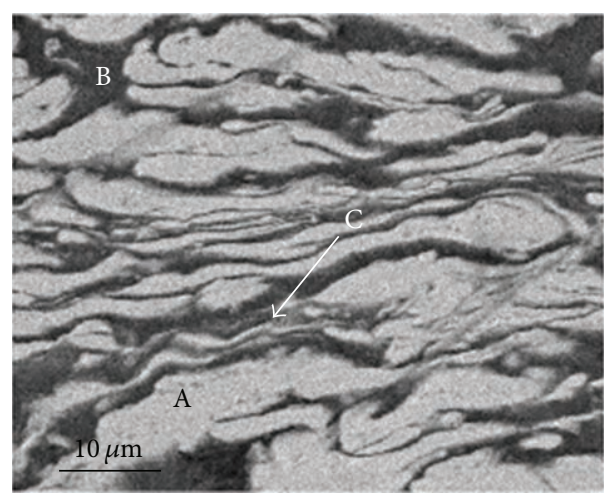

(a)
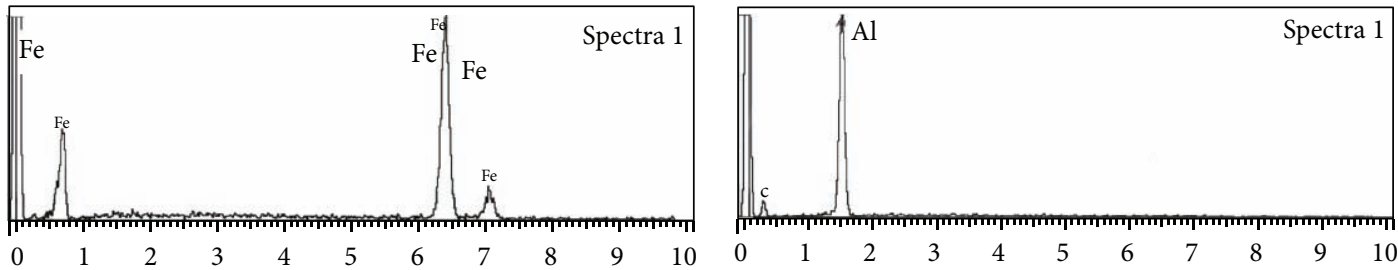

(A)

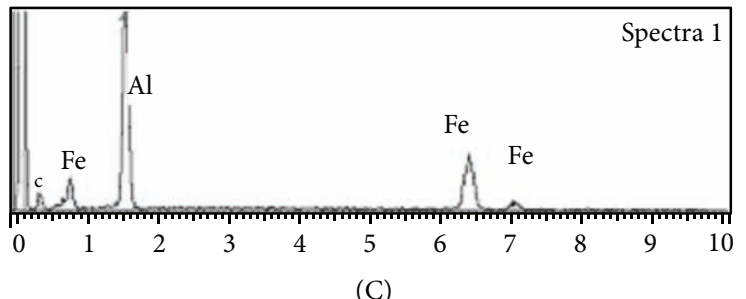

(B)

(b)

FIGURE 3: (a) BSE micrographs showing the transverse cut of coarser agglomerates (class C) to reveal the multilayer structure in each MAPmixtures. The bright layers (A) are Fe phase, and the dark ones (B) are Al phase. Between the finest multilayers (A and B), a layer with a intermediate color $(\mathrm{C})$ is observed and corresponds to a mix of Fe and Al. The EDX spectra of each contrasted layer (A, B, and C) are reported in (b).

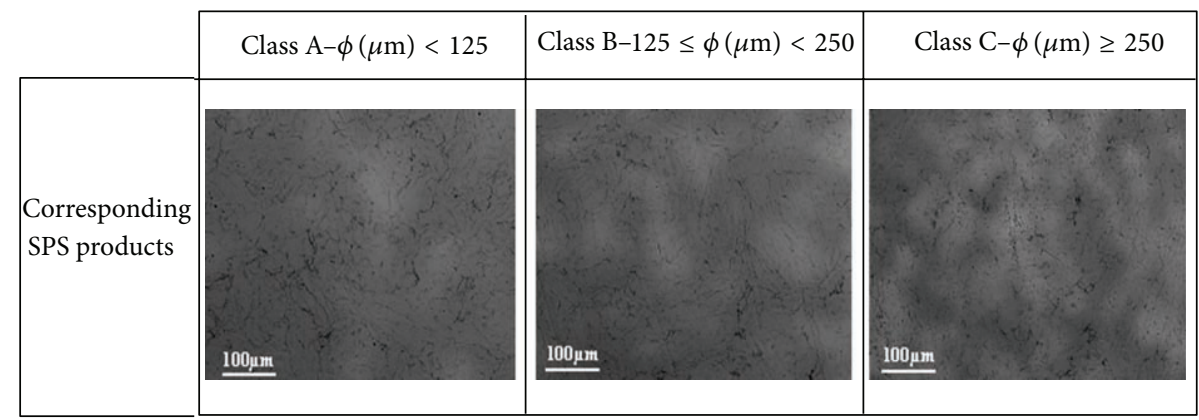

FIGURE 4: SEM (BSE mode) micrographs of products synthesized by SPS. These are performed on the transverse cut of each of them. The bright layers and the dark ones are $\mathrm{Fe}$ and $\mathrm{Al}$ phase in the agglomerates, respectively. Contrast of brightness is characteristic of the heterogeneity such as brighter area which can correspond to higher $\%$ at. Fe content.

supports the diffusion and, consequently, a true alloying takes place among the constituent elements.

\subsection{SPS Reactive Sintering. These MAP-mixtures were intro-} duced in the SPS apparatus for performing reactive sintering according to conditions previously described. The control of the SPS processing parameters has been found to allow the formation of a dense FeAl compound (close to 99\%) forming a microstructure with nanosized coherently diffracting domains [12]. TEM analyses have been found to reveal that the nanoorganization, especially the nanosize of the coherently diffracting domain size, was due to dislocation networks [12]. The beneficial effect of the SPS process on the densification was demonstrated elsewhere [11] showing 


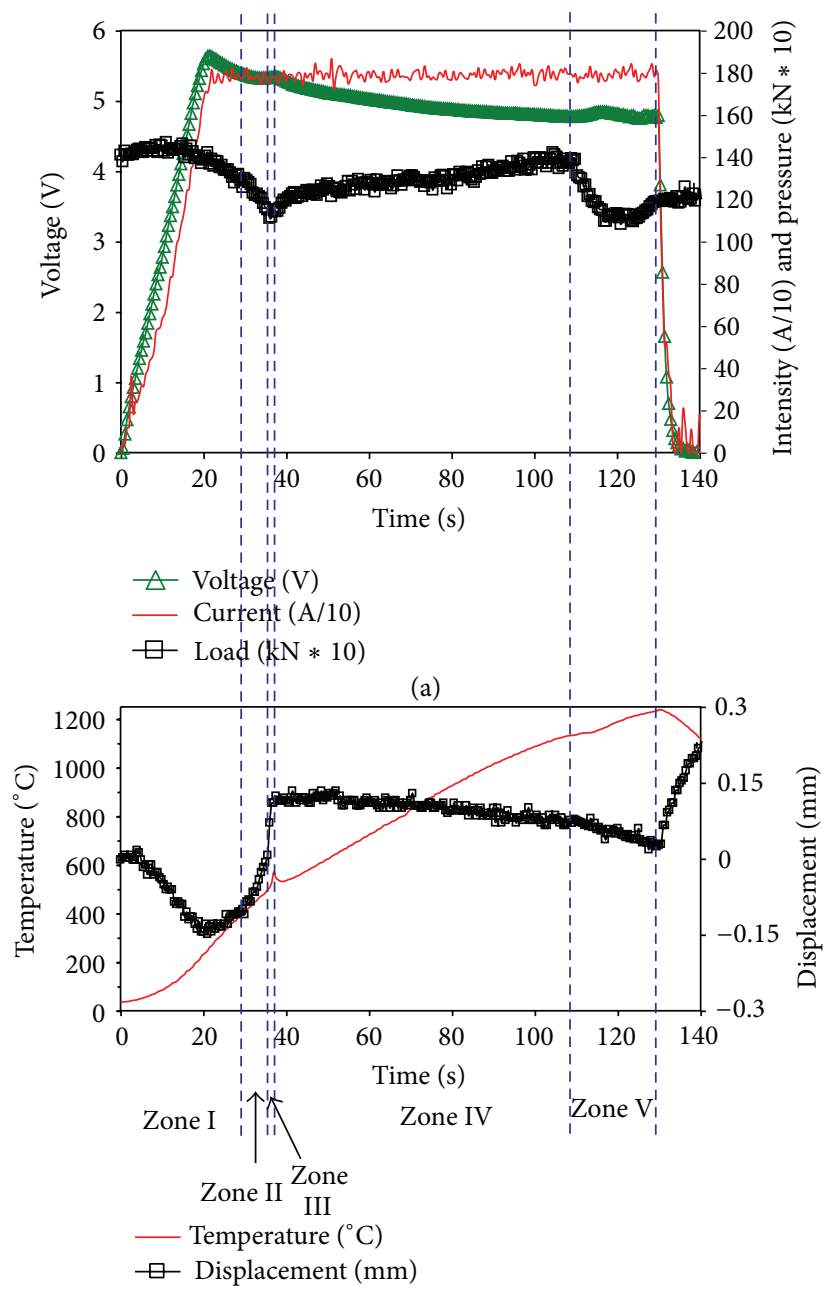

(b)

Figure 5: Evolutions of (a) the voltage $(\mathrm{V})$, intensity $(\mathrm{I} / 10)$ and pressure $(\mathrm{kN} \times 10)$ and of $(\mathrm{b})$ the temperature $(\mathrm{T})$ and the displacement versus the time of a sample sintered at $1750 \mathrm{~A}$ and $70 \mathrm{MPa}$.

that the relative density increased with the heating rate, the applied pressure, and the holding time up to a critical value. SEM observations (Figure 4) of the sintered sample showed clearly the presence of heterogeneous chemical compositions which differ versus MA-aggomerate size. In order to explain the origin of these heterogeneities, SPS-stop experiments were carried out using only larger MA-agglomerates (Class C) in which the chemical contrast seems to be stronger and also closer to expected FeAl stoichiometry (53\% at. Fe, Table 1). Figure 5(a) presents the evolution of SPS processing parameters versus the time during the reactive sintering from $\mathrm{Fe}+\mathrm{Al}$. In addition, as presented in Figure 5(b). From a fine analysis of such curves associated to reaction mechanisms, it is possible to describe the different sintering stages of the process leading to the formation of FeAl during a reactive sintering implying an exothermic reaction, that is, temperatures at which expansion and phase transformation take place. Such analysis allows selecting "interesting" temperatures that is performing SPS “stop." From Figure 5, five distinct successive stages can be highlighted labeled as zones I to V. XRD patterns from the SPS end-products quenched from different temperatures are presented in Figure 6. The corresponding microstructure contrast due to the difference in chemical composition is presented in Figure 7. The phase identification deduced from XRD characterization analysis and the chemical composition determined by EDX are also reported. It can be clearly stated that the nature of the phases determined by XRD (Figure 6) and microstructure observed by SEM (Figure 7) change versus the temperature. For describing all stages of the reactive sintering in the $\mathrm{Fe} / \mathrm{Al}$ system, the linear expansion (deduced from Figure 5(b)) and the relative density evolutions were plotted versus the temperature (Figure 8).

In Zone I, as can be observed (Figure 8), the displacement increases slowly from the room temperature to $400^{\circ} \mathrm{C}$. A SPSstop experiment carried out at $350^{\circ} \mathrm{C}$ revealed the absence of chemical interaction. The sample contained only Fe (bright layers) and $\mathrm{Al}$ (dark layers) like the initial green sample which is validated by the XRD analysis (Figure 6(b)). This confirms that no significant reaction occurs from RT up to $400^{\circ} \mathrm{C}$. Consequently, the slight expansion in Zone I was caused by the thermal expansion of particles, die, and gas. 


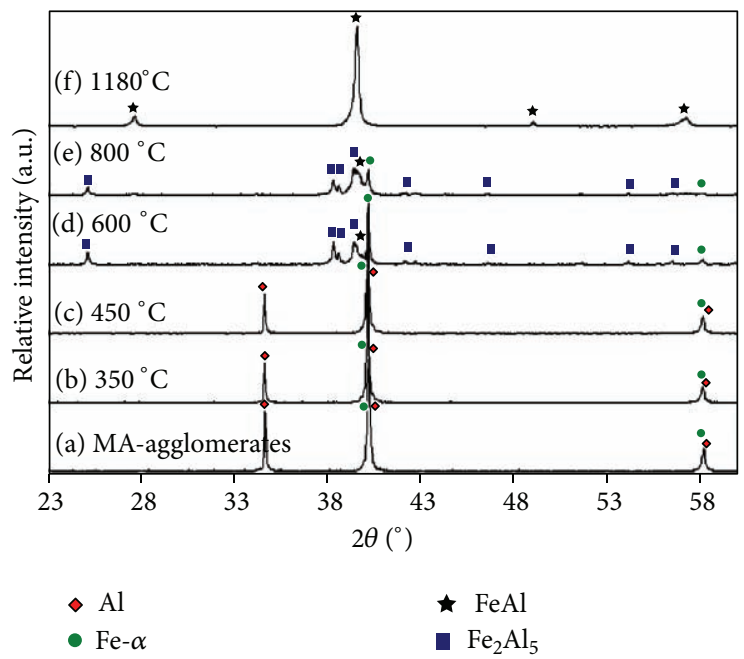

FIGURE 6: X-ray diffraction patterns (from (b) to (f)) versus temperature for quenched specimens to room temperature.

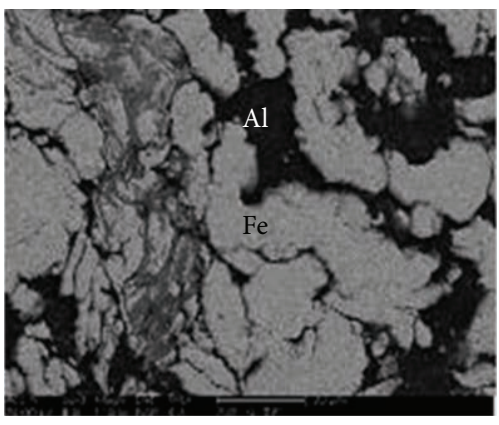

(a) $-450^{\circ} \mathrm{C}$



(b) $-600^{\circ} \mathrm{C}$

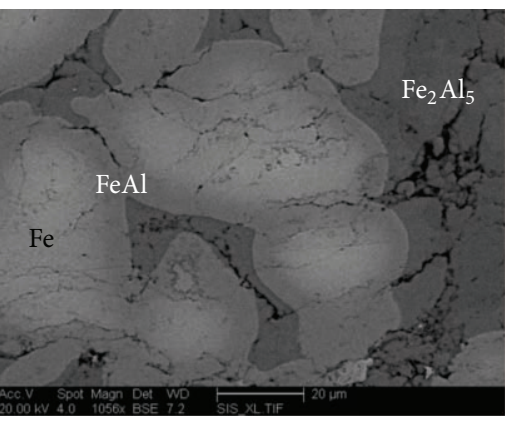

(c) $-800^{\circ} \mathrm{C}$

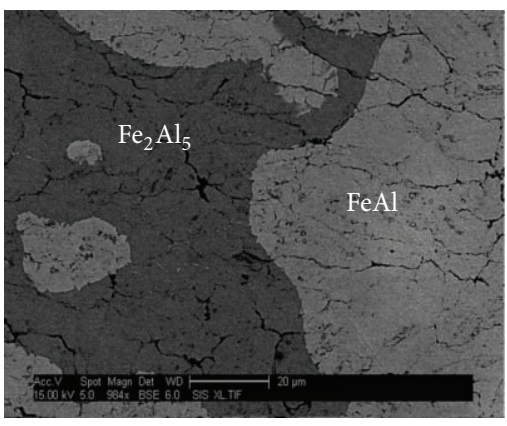

(d) $-1100^{\circ} \mathrm{C}$

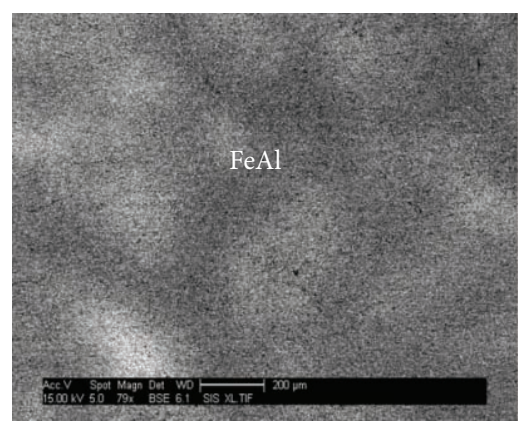

(e) $-1180^{\circ} \mathrm{C}-1235^{\circ} \mathrm{C}$

FIGURE 7: SEM (BSE mode) micrographs showing and comparing microstructure of samples quenched from different temperatures. Temperatures are characteristics of each zone relative to the reaction sequence of FeAl formation determined from the evolutions of the XRD patterns curves (Figure 6).

In Zone II, from $400^{\circ} \mathrm{C}$ to $500^{\circ} \mathrm{C}$, a slight shrinkage of the sample is observed (Figure 8(a)).

At $450^{\circ} \mathrm{C}$, for the sample quenched from $450^{\circ} \mathrm{C}$, an intermediate color can be observed at the $\mathrm{Fe}(\mathrm{s}) / \mathrm{Al}(\mathrm{s})$ interfaces (Figure 7(a)). Using energy dispersive spectroscopy (EDS), the dark gray phase surrounded by iron gets an atomic percent $\mathrm{Fe}$ equal to $\sim 30 \pm 2$. This latter can be identified as an amorphous or crystallized intermetallic phase rich in $\mathrm{Al}$ (such as $\mathrm{Fe}_{2} \mathrm{Al}_{5}$ according to the $\mathrm{Fe}-\mathrm{Al}$ phase diagram [27]) and/or as a solid solution of $\mathrm{Fe}(\mathrm{Al})$ or $\mathrm{Al}(\mathrm{Fe})$. In particular, Thompson [46] has pointed out that an interdiffusion is necessary between pure components at the interface before the nucleation of any intermetallic compound. In addition, it was reported [21] that at temperatures below $300^{\circ} \mathrm{C}$, the interdiffusion of $\mathrm{Fe}$ in f.c.c $\mathrm{Al}$ is faster for $\mathrm{Al}-\mathrm{Fe}$ diffusion couple. Above this temperature, the diffusion behavior is opposite; that is, interdiffusion of $\mathrm{Al}$ in b.c.c. Fe is faster. From calculated free energy at $450^{\circ} \mathrm{C}$, intermetallic compound can 


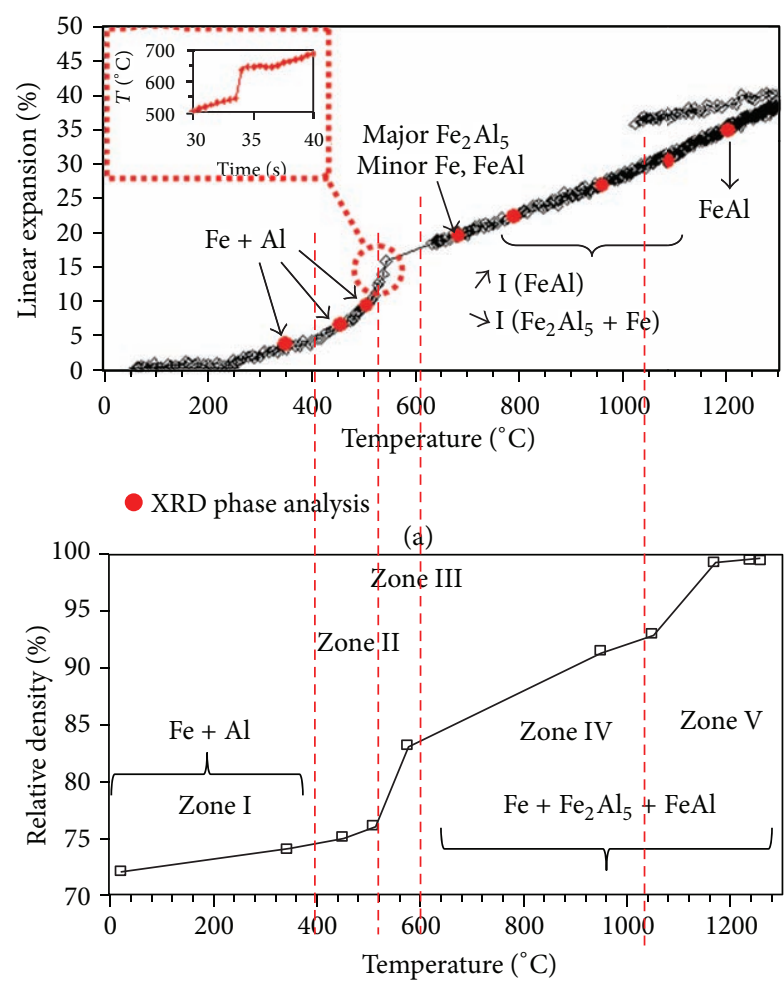

(b)

FIGURE 8: Evolution of (a) of the linear expansion during a SPS reactive sintering from $\mathrm{Fe}+\mathrm{Al}$ mixture. Red points correspond to XRD phase analysis presented in Figure 6. A zoom of the temperature profile showing the fast increase of the temperature characteristic of the exothermic reaction is inset. (b) Dependence of relative density of interrupted sample, that is, of the different phases (detected by XRD from Figure 6), as a function of temperature. In addition, five zones in agreement with Figure 5 are presented.

nucleate within the aluminum solid solution [47]. However, the amount of solute content $(\mathrm{Fe})$ in solid solution of $\mathrm{Al}$ is too small to be detected.

In Zone III, a sharp temperature elevation $\left(3780^{\circ} \mathrm{C}\right.$. $\mathrm{min}^{-1}$ ) from $500^{\circ} \mathrm{C}$ to $600^{\circ} \mathrm{C}$ is observed simultaneously as a significant shrinkage which is validated by the faster stage of densification (Figure 8). These evolutions are characteristics of the exothermic reaction occurring between $\mathrm{Fe}$ and $\mathrm{Al}$ powders. This latter is confirmed by X-ray analysis which shows the presence of an unreacted $\mathrm{Fe}$ and the formation of the aluminum rich $\mathrm{Fe}_{2} \mathrm{Al}_{5}$ (Figure 6(d)) and of a minor amount of $\mathrm{FeAl}$. The formation of $\mathrm{Fe}_{2} \mathrm{Al}_{5}$ is detectable only from $600^{\circ} \mathrm{C}$ whereas it can exist at lower temperature. As previously observed, the dark gray phase is confirmed as $\mathrm{Fe}_{2} \mathrm{Al}_{5}$ ( $\sim 30 \%$ at. Fe). The intermetallic compound is formed around the partially unreacted Fe particle (bright layer). The interface between the $\mathrm{Fe}_{2} \mathrm{Al}_{5}$ layer and $\mathrm{Fe}$ grain is irregular due to the tongue-like morphology of the $\mathrm{Fe}_{2} \mathrm{Al}_{5}$ layer. Similar morphology was observed during dipping solid Fe in liquid aluminum $[48,49]$. It can be concluded that at this stage, despite the fact that melting point of $\mathrm{Al}$ was not reached $\left(660^{\circ} \mathrm{C}\right)$, aluminum has totally reacted to form iron aluminide and left behind large pores (Figure $7(\mathrm{~b})$ ) certainly due to

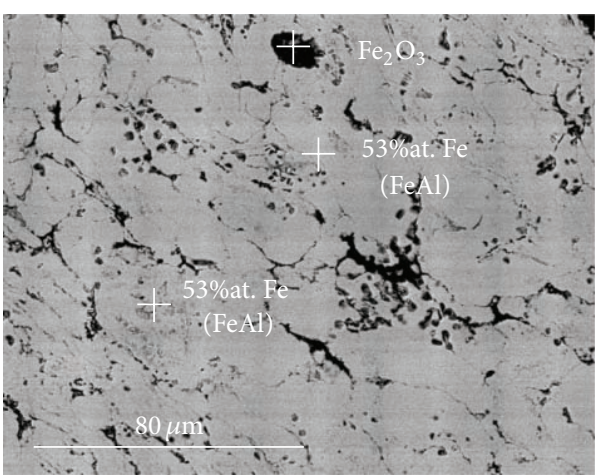

FIGURE 9: SEM (BSE mode) micrographs of a homogeneous single phase $\mathrm{FeAl}$ after thermal treatment $\left(1000^{\circ} \mathrm{C}, 30 \mathrm{~min}\right)$ on sample containing $\mathrm{Fe}+\mathrm{Fe}_{2} \mathrm{Al}_{5}+\mathrm{FeAl}$ phases presented in Figures 6(e) and 7(c).

a local temperature higher than measured temperature. As reported by different authors [29], the reaction demonstrated to be always accompanied by an expansion of the sample due to the solid state exothermic reaction $2 \mathrm{Fe}(\mathrm{s})+5 \mathrm{Al} \Rightarrow \mathrm{Fe}_{2} \mathrm{Al}_{5}$ which occurred at $\sim 560-565^{\circ} \mathrm{C}$.

Then, in Zone IV from $600^{\circ} \mathrm{C}$ to $1100^{\circ} \mathrm{C}$, it can be seen that the amount of $\mathrm{FeAl}$ increases on the expense of $\mathrm{Fe}_{2} \mathrm{Al}_{5}$ and Fe (Figure 6(e)). These observations are confirmed by high resolution SEM images (Figure 7(c)). Three uniform welldistinguished phases which differ in contrast can be observed. However the amount of FeAl is very small even after the second reaction. The EDS analysis obtained from these regions indicate that between $\mathrm{Fe}$ (bright grain) and aluminum rich $\mathrm{Fe}_{2} \mathrm{Al}_{5}$ there is another layer (light grey layers) exhibiting narrow morphology rings with Fe concentration much higher (55\% at.) than expected in $\mathrm{Fe}_{2} \mathrm{Al}_{5}$ (Figure 7). These may be the rings of the aggregates. These layers are believed to be consisting of FeAl or a mixture of FeAl with $\mathrm{Fe}$ or $\mathrm{Fe}_{2} \mathrm{Al}_{5}$. At higher temperature $\left(1100^{\circ} \mathrm{C}\right)$, according to SEM analysis (Figure $7(\mathrm{~d})$ ), the amounts of $\mathrm{Fe}_{2} \mathrm{Al}_{5}$ and Fe still decrease whereas the quantity of FeAl increases. Such observations can be explained from diffusion couple of species. As reported by Maitra and Gupta [30] during the formation of FeAl, the microstructure of the diffusion couple has revealed that exist two Kirkendall planes: one at the $\mathrm{Fe} / \mathrm{FeAl}$ interface and, the other at the $\mathrm{FeAl} / \mathrm{Fe}_{2} \mathrm{Al}_{5}$ interface on the $\mathrm{Fe}_{2} \mathrm{Al}_{5}$ side. For the Kirkendall plane at $\mathrm{Fe} / \mathrm{FeAl}$ interface, it can be inferred that Fe diffused faster $\left(\sim \times 10^{4}\right)$ than $\mathrm{Al}$ in the Fe-rich part of FeAl. A similar conclusion can be drawn for the other Kirkendall plane in agreement with the diffusivity values [50]. These observations are confirmed from activation energy for the growth of the FeAl layer. The activation energy for the growth of the FeAl layer is larger $\left(180 \mathrm{~kJ} \cdot \mathrm{mol}^{-1}\right)$ than that for the diffusion of iron atoms into $\mathrm{Fe}_{2} \mathrm{Al}_{5}\left(141 \mathrm{~kJ} \cdot \mathrm{mol}^{-1}\right)$ and is smaller than that for the diffusion of aluminum atoms into $\mathrm{FeAl}\left(340 \mathrm{~kJ} \cdot \mathrm{mol}^{-1}\right)$ [51]. It was identified that the growth of all intermetallic layers was controlled by the diffusion of $\mathrm{Fe}$ atoms into the Al-richer intermetallic layers [52]. The growth of the FeAl layer was likely controlled by the diffusion of iron atoms into the $\mathrm{Fe}_{2} \mathrm{Al}_{5}$ layers. 




FIgURE 10: Phase evolution from Fe/Al MAP-mixtures for producing pure FeAl compound by reactive sintering.

Finally, in Zone $\mathrm{V}$ from $1100^{\circ} \mathrm{C}$ to $1235^{\circ} \mathrm{C}$, the evolution of the SPS curves corresponds to the formation of FeAl. At $1180^{\circ} \mathrm{C}$, only XRD peaks of FeAl are observed (Figure 6(f)). $\mathrm{FeAl}$ compound was formed to exhibit a micrometric grain size ranging from 1 to $6 \mu \mathrm{m}$ [12]. Nevertheless, from the observation of BSE micrograph, whereas the previous areas corresponding to $\mathrm{Fe}$ and $\mathrm{Fe}_{2} \mathrm{Al}_{5}$ disappear, a modulation of contrast can be clearly observed (Figure 7(e)). Such observations can be explained by the chemical contrast present at the submillimeter-scale (EDX) $[10,11]$ with a variability of $\mathrm{Al}$ content in the range of $36-47 \%$. The specificities can be introduced by the melting of $\mathrm{Fe}_{2} \mathrm{Al}_{5}$ at $1171^{\circ} \mathrm{C}$ according to the $\mathrm{Fe}-\mathrm{Al}$ phase diagram [27]. Hence, the melting of $\mathrm{Fe}_{2} \mathrm{Al}_{5}$ allows a faster shrinkage and leads to a fully dense compound; that is, the density of the compact reaches $99.5 \%$ TD. No macroporosity can be observed in SEM image (Figure 7(e)) which is confirmed from $\mathrm{Hg}$ porosimetry analysis, and no open porosity was detected. It is obvious that hot pressure applied during SHS allows full-densification of material.

To confirm the role of $\mathrm{Fe}_{2} \mathrm{Al}_{5}$ in the formation of $\mathrm{FeAl}$, an additional experiment was performed on the sample quenched from $800^{\circ} \mathrm{C}$ in order to get FeAl from solid state reaction between $\mathrm{Fe}_{(\mathrm{s})} / \mathrm{Fe}_{2} \mathrm{Al}_{5(\mathrm{~s})} / \mathrm{FeAl}_{(\mathrm{s})}$ phases. The sample was heated for $30 \mathrm{~min}$ at $1000^{\circ} \mathrm{C}$, below the melting point of $\mathrm{Fe}_{2} \mathrm{Al}_{5}$. Compared to previous $\mathrm{FeAl}$ compounds formed, a single phase material (with pores) was formed (Figure 9) with $94 \%$ relative density. After polishing of the sample to eliminate oxide layers, local phase analysis (EDS) on several zones showed that the sample composition is homogeneous and corresponds to the expected composition (53 at.\% Fe, Figure 9). Characteristics are consistent with those obtained by Gedevanishvili and Deevi [29] at $900^{\circ} \mathrm{C}$. Homogeneous
FeAl compounds can be formed via a solid state reaction. Consequently, it is expected that the new FeAl phase formed during the melting of $\mathrm{Fe}_{2} \mathrm{Al}_{5}$ has a different formation mechanisms than the FeAl synthesized at lower temperature. This study confirms the necessity on the one hand, to follow the evolutions of the phase nature and of their respective domains of composition and, on the other hand, to understand the sequence of phase formation, the interface type, the morphology of interfaces, and the growth mechanism. Thus, it is possible to suggest a reaction mechanism for producing pure $\mathrm{FeAl}$ (Figure 10). Whatever the SPS conditions, the formation of FeAl occurred in three steps: the formation of a solid solution $\mathrm{Fe}(\mathrm{Al})$ followed by a solid state reaction of $\mathrm{Fe}_{2} \mathrm{Al}_{5}$ to the interfaces of $\mathrm{Fe}(\mathrm{s}) / \mathrm{Al}(\mathrm{s})$ and, then FeAl. Nevertheless, it is not possible to conclude the fact that such reactions are competitive or successive. The formation of $\mathrm{Fe}_{2} \mathrm{Al}_{5}$ is prejudicial to elaborate dense $\mathrm{FeAl}$ in one step from $\mathrm{Al}$ liquid phase [15]. To limit the reaction duration, it is necessary to go through the melting of $\mathrm{Fe}_{2} \mathrm{Al}_{5}$. This latter phase, combined to the presence of $\mathrm{Fe}(\mathrm{s})$, is responsible for the original characteristics of the $\mathrm{FeAl}$ compounds. In agreement with others intermetallics, an increase of the heating rate will reduce the duration of precombustion reaction and, consequently the formation of $\mathrm{Fe}_{2} \mathrm{Al}_{5}$. A higher heating rate will promote Fe-solid-Al-liquid reaction which results in the production of pure nanostructured FeAl compounds [53] whereas the presence of $\mathrm{Fe}_{2} \mathrm{Al}_{5}$ leads to a stoichiometry gap. Consequently, the heterogeneous characteristics of MAagglomerates according to their size which are considered as SHS microreactors reinforce the obligation of their check. They are responsible for the FeAl chemical heterogeneities which depend on the reaction path. 


\section{Conclusion}

This study gives a fine description of the formation of $\mathrm{Fe} / \mathrm{Al}$ MA-agglomerates using a high energy planetary ball-mill. It has been demonstrated that mechanical activation resulted in the formation of micrometer size aggregates composed of nanostructured $\mathrm{Fe} / \mathrm{Al}$ multilayers with heterogeneous characteristics themselves. These latter are responsible for the heterogeneous characteristics of the subsequent dense "nanostructured" FeAl compounds synthesized by SPS reactive sintering. A system presenting an "ideal" nanometer size multilayer system is obtained when the larger aggregates are formed. Consequently, for this ball-milling conditions, that is, P4 (150/-200/4 h), the optimal mixture resulted from the 3rd ball-milling without cleaning tools and had the coarsest studied granulometry ( $\phi \geq 250 \mu \mathrm{m}$, i.e., Class C). In addition, it is essential for each agglomerate size to adapt reactive sintering parameters for limiting $\mathrm{FeAl}$ chemical heterogeneities.

The dense FeAl intermetallics synthesized via a mechanically activated reactive sintering process have been shown to exhibit some chemical heterogeneity. To produce FeAl materials with perfectly controlled characteristics, the sequences of phases formed during the sintering of MAP-mixtures $(\mathrm{Fe}+$ $\mathrm{Al})$ were identified by X-ray diffraction, scanning electron microscopy back scattered electrons coupled with energy dispersive X-ray spectrometry, and density measurements. The results were correlated to the temperature profile and the shrinkage curve occurring during flash sintering. It was found that the formation of the intermediate phase $\mathrm{Fe}_{2} \mathrm{Al}_{5}$ at $\sim 510^{\circ} \mathrm{C}$ was associated with an exothermic reaction and a linear expansion and followed by the formation of small amount of FeAl. The conversion to nanoorganized $\mathrm{FeAl}$ is complete at higher temperatures than the melting point of $\mathrm{Fe}_{2} \mathrm{Al}_{5}\left(1170^{\circ} \mathrm{C}\right)$. The formation of two types of iron aluminide intermetallics. (i.e., with distinct reaction mechanisms) seems to be at origin of the FeAl specificities. Consequently, it is essential to limit the formation of $\mathrm{Fe}_{2} \mathrm{Al}_{5}$ by solid state reaction and to promote the direct reaction between $\mathrm{Fe}(\mathrm{s})$ and $\mathrm{Al}(\mathrm{l})$ by a control of the mechanical activation and reactive sintering conditions.

\section{Acknowledgment}

The authors acknowledge the financial support of the "Ministère de l'Enseignement Supérieur et de la Recherche."

\section{References}

[1] D. G. Morris and M. A. Morris-Muñoz, "The influence of microstructure on the ductility of iron aluminides," Intermetallics, vol. 7, no. 10, pp. 1121-1129, 1999.

[2] M. A. Morris-Muñoz, A. Dodge, and D. G. Morris, "Structure, strength and toughness of nanocrystalline FeAl," Nanostructured Materials, vol. 11, no. 7, pp. 873-885, 1999.

[3] L. D'Angelo, L. D'Onofrio, and G. Gonzalez, "Nanophase intermetallic FeAl obtained by sintering after mechanical alloying," Journal of Alloys and Compounds, vol. 483, no. 1-2, pp. 154-158, 2009.
[4] T. Grosdidier, H. L. Liao, S. Lenhard, A. Tidu, and S. Revol, "Processing and characterisation of nanocrystalline iron aluminide coatings prepared by thermal spraying of milled powders," Journal de Physique I, vol. 11, pp. 11-18, 2001.

[5] J. Gang, J.-P. Morniroli, and T. Grosdidier, "Nanostructures in thermal spray coatings," Scripta Materialia, vol. 48, no. 12, pp. 1599-1604, 2003.

[6] G. Ji, T. Grosdidier, and J. P. Morniroli, "Microstructure of a high-velocity oxy-fuel thermal sprayed nanostructured coating obtained from milled powder," Metallurgical and Materials Transactions A, vol. 38, no. 10, pp. 2455-2463, 2007.

[7] T. Grosdidier, G. Ji, F. Bernard, E. Gaffet, Z. A. Munir, and S. Launois, "Synthesis of bulk FeAl nanostructured materials by HVOF spray forming and spark plasma sintering," Intermetallics, vol. 14, no. 10-11, pp. 1208-1213, 2006.

[8] G. Ji, T. Grosdidier, F. Bernard, S. Paris, E. Gaffet, and S. Launois, "Bulk FeAl nanostructured materials obtained by spray forming and spark plasma sintering," Journal of Alloys and Compounds, vol. 434-435, pp. 358-361, 2007.

[9] T. Skiba, P. Haušild, M. Karlík, K. Vanmeensel, and J. Vleugels, "Mechanical properties of spark plasma sintered FeAl intermetallics," Intermetallics, vol. 18, no. 7, pp. 1410-1414, 2010.

[10] S. Paris, C. Valot, L. Gosmain, E. Gaffet, F. Bernard, and Z. Munir, "Investigation of mechanically activated field-activated pressure-assisted synthesis processing parameters for producing dense nanostructured FeAl," Journal of Materials Research, vol. 18, no. 10, pp. 2331-2338, 2003.

[11] S. Paris, E. Gaffet, F. Bernard, and Z. A. Munir, "Spark plasma synthesis from mechanically activated powders: a versatile route for producing dense nanostructured iron aluminides," Scripta Materialia, vol. 50, no. 5, pp. 691-696, 2004.

[12] G. Ji, D. Goran, F. Bernard, T. Grosdidier, E. Gaffet, and Z. A. Munir, "Structure and composition heterogeneity of a FeAl alloy prepared by one-step synthesis and consolidation processing and their influence on grain size characterization," Journal of Alloys and Compounds, vol. 420, no. 1-2, pp. 158-164, 2006.

[13] A. S. Rogachev, N. A. Kochetov, V. V. Kurbatkina et al., "Microstructural aspects of gasless combustion of mechanically activated mixtures. I. High-speed microvideorecording of the NiAl composition," Combustion, Explosion and Shock Waves, vol. 42, no. 4, pp. 421-429, 2006.

[14] C. Gras, D. Vrel, E. Gaffet, and F. Bernard, "Mechanical activation effect on the self-sustaining combustion reaction in the Mo-Si system," Journal of Alloys and Compounds, vol. 314, no. 1-2, pp. 240-250, 2001.

[15] F. Charlot, F. Bernard, E. Gaffet, D. Klein, and J. C. Niepce, "In situ time-resolved diffraction coupled with a thermal I.R. camera to study mechanically activated SHS reaction: case of Fe-Al binary system," Acta Materialia, vol. 47, no. 2, pp. 619-629, 1999.

[16] F. Charlot, E. Gaffet, B. Zeghmati, F. Bernard, and J. C. Niepce, "Mechanically activated synthesis studied by X-ray diffraction in the Fe-Al system," Materials Science and Engineering A, vol. 262, no. 1-2, pp. 279-288, 1999.

[17] D. E. Alman and N. S. Stoloff, "Powder fabrication of monolithic and composite NiAl," International Journal of Powder Metallurgy, vol. 27, no. 1, pp. 29-41, 1991.

[18] Y. Champion and J. Bigot, "Synthesis and structural analysis of aluminum nanocrystalline powders," Nanostructured Materials, vol. 10, no. 7, pp. 1097-1110, 1998.

[19] F. Charlot, Etude et compréhension des réactions auto-entretenues activées mécaniquement. Elaboration du composé FeAl 
nanostructuré [Ph.D. thesis], Université de Bourgogne, Dijon, France, 1999.

[20] Z. A. Munir, F. Charlot, F. Bernard, and E. Gaffet, "One-step synthesis and consolidation of nano-phase materials," U.S Patent, no. 6, 200, 515, March 2001.

[21] S. R. Teixeira, P. H. Dionisio, E. F. da Silveria, F. L. Freire Jr., W. H. Schreiner, and I. J. R. Baumvol, "Interdiffusion and reaction in the FeAl bilayer: I: rutherford backscattering analysis of furnace-annealed samples," Materials Science and Engineering, vol. 96, pp. 267-277, 1987.

[22] M. Abdellaoui, T. Barradi, and E. Gaffet, "Mechanism of mechanical alloying phase formation and related magnetic and mechanical properties in the FeSi system," Journal of Alloys and Compounds, vol. 198, no. 1-2, pp. 155-164, 1993.

[23] M. Abdellaoui and E. Gaffet, "The physics of mechanical alloying in a planetary ball mill: mathematical treatment," Acta Metallurgica et Materialia, vol. 43, no. 3, pp. 1087-1098, 1995.

[24] M. Tokita, "Trends in advanced spark plasma sintering systems and technology. Functionnally gradient materials and unique synthetic processing methods from next generation of powder technology," Journal of Japan Society Powder Technology, vol. 30, pp. 790-804, 1993.

[25] K. F. Kobayashi, N. Tachibana, and P. H. Shingu, "Formation of amorphous Al-Cr alloys by mechanical alloying of elemental aluminium and chromium powders," Journal of Materials Science, vol. 25, no. 7, pp. 3149-3154, 1990.

[26] M. V. Zdujic, K. F. Kobayashi, and P. H. Shingu, "Structural changes during mechanical alloying of elemental aluminium and molybdenum powders," Journal of Materials Science, vol. 26, no. 20, pp. 5502-5508, 1991.

[27] O. Kubaschewski, IRON-Binary Phase Diagrams, Springer, 1986.

[28] D. L. Zhang and D. Y. Ying, "Solid state reactions in nanometer scaled diffusion couples prepared using high energy ball milling," Materials Science and Engineering A, vol. 301, no. 1, pp. 90-96, 2001.

[29] S. Gedevanishvili and S. C. Deevi, "Processing of iron aluminides by pressureless sintering through $\mathrm{Fe}+\mathrm{Al}$ elemental route," Materials Science and Engineering A, vol. 325, no. 1-2, pp. 163$176,2002$.

[30] T. Maitra and S. P. Gupta, "Intermetallic compound formation in Fe-Al-Si ternary system-part II," Materials Characterization, vol. 49, no. 4, pp. 293-311, 2002.

[31] E. Godlewska, S. Szczepanik, R. Mania, J. Krawiarz, and S. Koziñski, "FeAl materials from intermetallic powders," Intermetallics, vol. 11, no. 4, pp. 307-312, 2003.

[32] G. Cabouro, S. le Gallet, S. Chevalier, E. Gaffet, Y. Grin, and F. Bernard, "Dense $\mathrm{Mosi}_{2}$ produced by reactive flash sintering: control of $\mathrm{Mo} / \mathrm{Si}$ agglomerates prepared by high-energy ball milling," Powder Technology, vol. 208, no. 2, pp. 526-531, 2011.

[33] J. H. Perepezko, R. J. Hebert, and G. Wilde, "Synthesis of nanostructures from amorphous and crystalline phases," Materials Science and Engineering A, vol. 375-377, no. 1-2, pp. 171-177, 2004.

[34] D. Oleszak and P. H. Shingu, "Mechanical alloying in the FeAl system," Materials Science and Engineering A, vol. 181-182, pp. 1217-1221, 1994.

[35] E. Hellstern, H. J. Fecht, Z. Fu, and W. L. Johnson, "Structural and thermodynamic properties of heavily mechanically deformed Ru and AlRu," Journal of Applied Physics, vol. 65, no. 1, pp. 305-310, 1989.
[36] P. Baláž, M. Achimovičová, M. Baláž et al., "Hallmarks of mechanochemistry: from nanoparticles to technology," Chemical Society Reviews, 2013.

[37] C. Suryanarayana, "Mechanical alloying and milling," Progress in Materials Science, vol. 46, no. 1-2, pp. 1-184, 2001.

[38] E. Gaffet and F. Bernard, "Mechanically activated powder metallurgy processing: a versatile way towards nanomaterials synthesis," Annales de Chimie: Science des Materiaux, vol. 27, no. 6, pp. 47-59, 2002.

[39] E. Gaffet and G. le Caër, "Mechanical processing for nanomaterials," in Encyclopedia of Nanoscience and Nanotechnology, $\mathrm{H}$. S. Nalwa, Ed., vol. 5, pp. 91-129, American Scientific Publishers, 2004.

[40] E. Gaffet, "Planetary ball-milling: an experimental parameter phase diagram," Materials Science and Engineering A, vol. 132, pp. 181-193, 1991.

[41] E. Gaffet, "Dynamic equilibrium induced by ball milling in the NiZr system," Materials Science and Engineering A, vol. 119, pp. 185-197, 1989.

[42] E. Gaffet, "Ball milling: an E- $v$-T parameter phase diagram," Materials Science and Engineering A, vol. 135, pp. 291-293, 1991.

[43] S. Vives, E. Gaffet, and C. Meunier, "X-ray diffraction line profile analysis of iron ball milled powders," Materials Science and Engineering A, vol. 366, no. 2, pp. 229-238, 2004.

[44] O. Boytsov, A. I. Ustinov, E. Gaffet, and F. Bernard, "Correlation between milling parameters and microstructure characteristics of nanocrystalline copper powder prepared via a high energy planetary ball mill," Journal of Alloys and Compounds, vol. 432, no. 1-2, pp. 103-110, 2007.

[45] M. S. El-Eskandarany, K. Aoki, and K. Suzuki, "Solid state formation of Al-TM (TM: Ti, Zr, Nb and Ta) amorphous alloys by mechanical rod milling, mechanical alloying," Materials Science Forum, vol. 88-90, pp. 81-88, 1992.

[46] C. V. Thompson, "On the role of diffusion in phase selection during reactions at interfaces," Journal of Materials Research, vol. 7, no. 2, pp. 367-373, 1992.

[47] P. Bhattacharya, K. N. Ishihara, and K. Chattopadhyay, "FeAl multilayers by sputtering: heat treatment and the phase evolution," Materials Science and Engineering A, vol. 304-306, no. 1-2, pp. 250-254, 2001.

[48] J.-M. Lee, S.-B. Kang, T. Sato, H. Tezuka, and A. Kamio, "Evolution of iron aluminide in $\mathrm{Al} / \mathrm{Fe}$ in situ composites fabricated by plasma synthesis method," Materials Science and Engineering A, vol. 362, no. 1-2, pp. 257-263, 2003.

[49] K. Bouché, F. Barbier, and A. Coulet, "Intermetallic compound layer growth between solid iron and molten aluminium," Materials Science and Engineering A, vol. 249, no. 1-2, pp. 167175, 1998.

[50] E. A. Brande, Ed., Smithells Metals Reference Book, Butterworth, 1983.

[51] H. Bakker and H. Mehrer, Eds., Diffusion in Solid Metals and Alloys, vol. 26 of Numerical Data and Functional Relationship in Science and Technology, Springer, 1990.

[52] S. Kobayashi and T. Yakou, "Control of intermetallic compound layers at interface between steel and aluminum by diffusiontreatment," Materials Science and Engineering A, vol. 338, no. 1-2, pp. 44-53, 2002.

[53] F. Bernard, F. Charlot, E. Gaffet, and Z. A. Munir, "Onestep synthesis and consolidation of nanophase iron aluminide," Journal of the American Ceramic Society, vol. 84, no. 5, pp. 910914, 2001. 

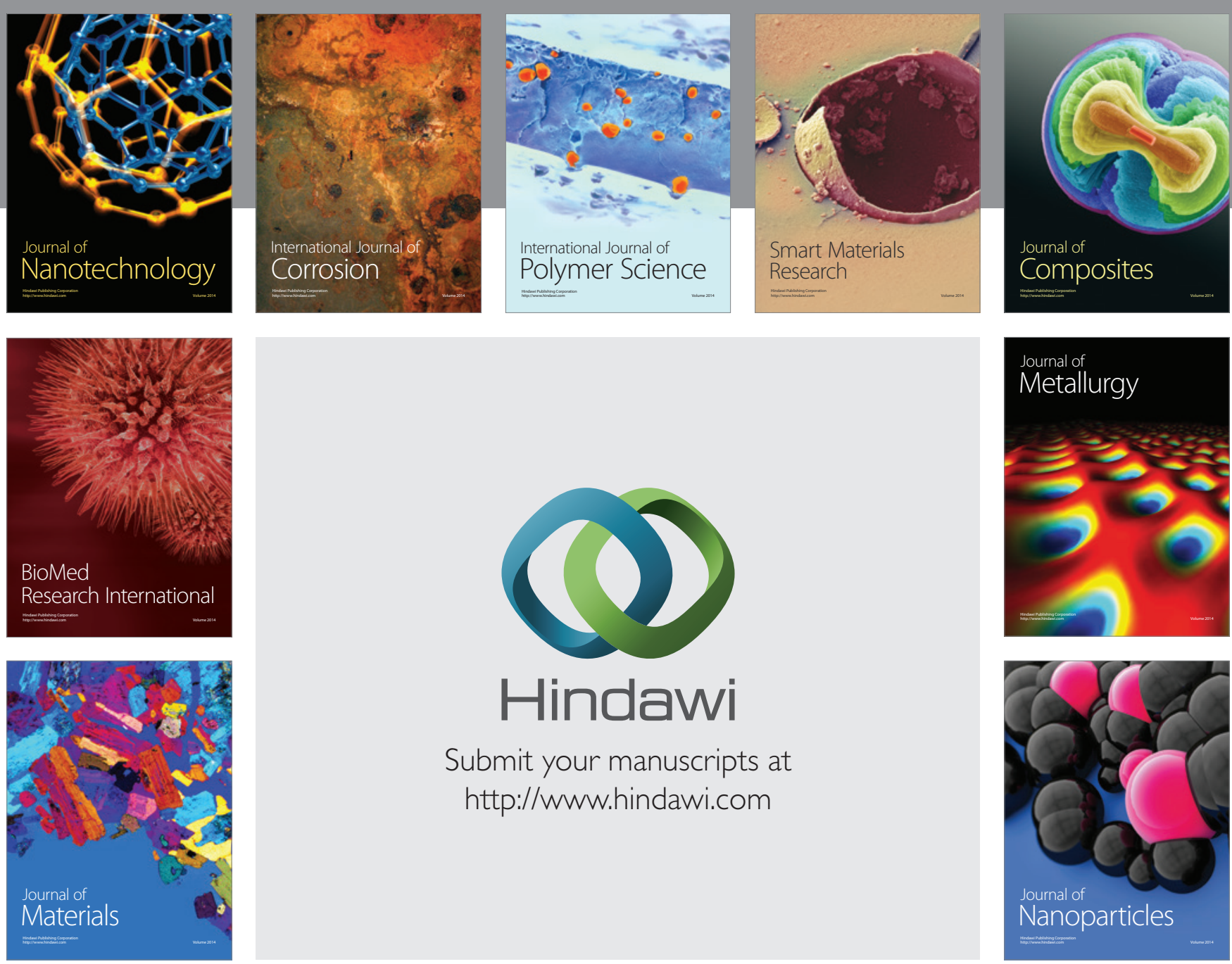

Submit your manuscripts at http://www.hindawi.com
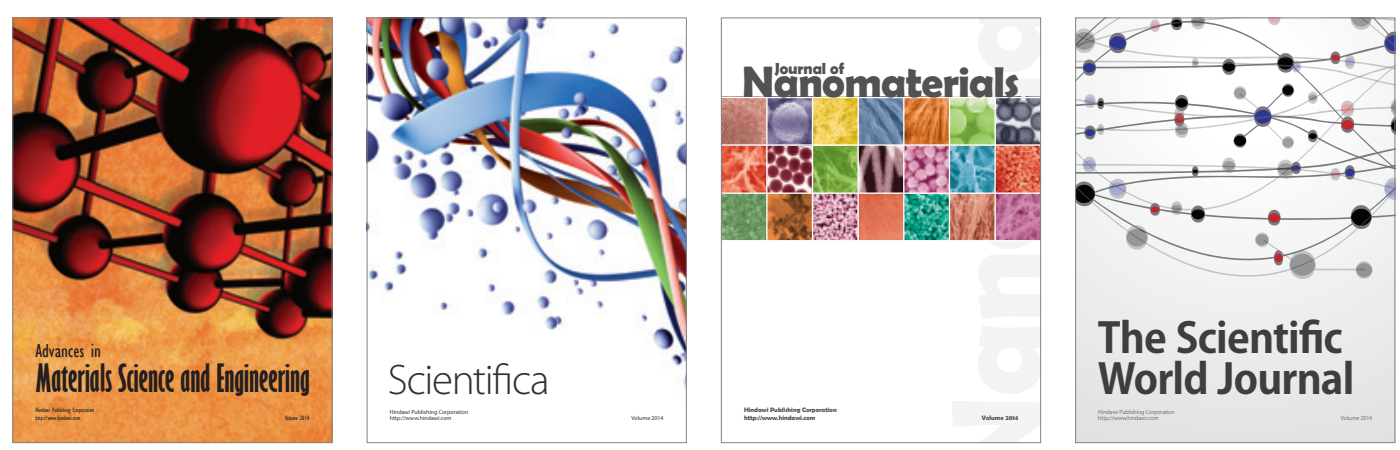

\section{The Scientific World Journal}
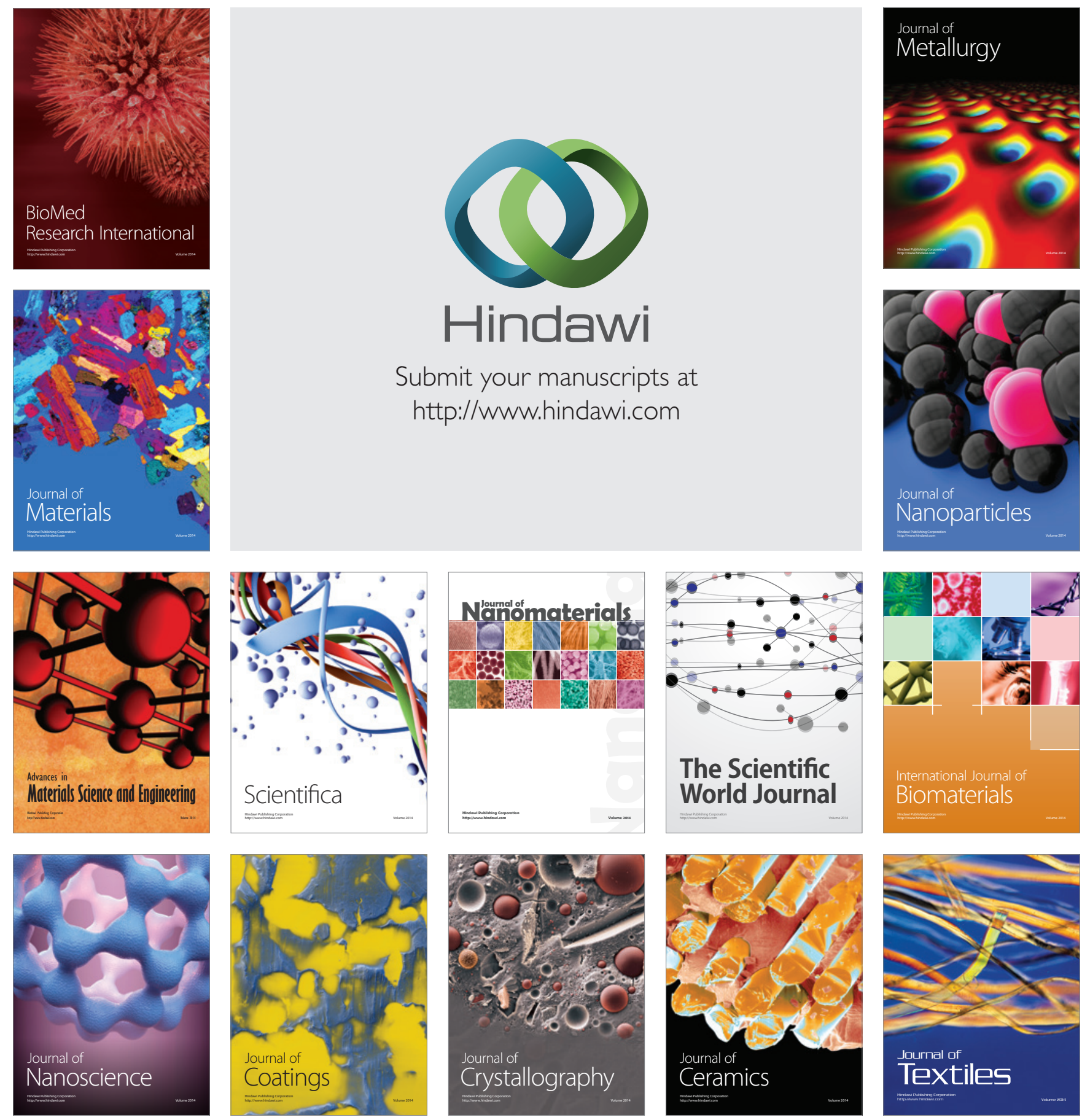